DOI: $10.19113 /$ sdufenbed.543986

\title{
Inductance Selection Criteria and Design Steps for Power Electronics Applications
}

\author{
Mustafa Ergin ŞAHIN ${ }^{* 1}$
}

${ }^{1}$ Recep Tayyip Erdoğan Üniversitesi, Mühendislik Fakültesi, Elektrik Elektronik Bölümü, 53100, Rize, Türkiye

(Alınış / Received: 24.03.2019, Kabul / Accepted: 17.06.2020, Online Yayınlanma / Published Online: 20.12.2020)

\section{Keywords}

Inductance selection and design,

Ferrite cores and Litz wire, Skin effect in inductance, Inductance efficiency, Power electronics converters

\begin{abstract}
The power electronics circuits are indispensable devices today for renewable energy applications and for storing energy. One of the main components of this power electronic circuits is the inductance. The inductance working as a live heart, store the energy and pumps the energy from the source to the load in converters, and supply continuously the current of the circuit to the load. The energy efficiency in the system depends on the inductance efficiency. So, a well-designed inductance is very important in order to operate the converter in continuous mode so the current flow is uninterruptible. In this paper, inductance selection criteria for the converters are investigated to work the converter in continuous mode from the literature and solved for the limit value condition equation. Also, the design steps of an inductance including necessary calculations are shown with an example application. The cores and wires effect to the inductance efficiency is also investigated in this paper. An inductance using Ferrite core and Litz wire is proposed and designed experimentally for a converter circuit. Measurements to determine the inductance value was shown. Also, the inductance current variations for higher frequencies are investigated, and used in the converter is shown.
\end{abstract}

\section{Endüktans Seçim Kriteri ve Güç Elektroniği Uygulamaları için Tasarım Aşamaları}

\section{Anahtar Kelimeler}

Endüktans seçim ve tasarımı, Ferit çekirdekler ve litz teli, Endüktans deri olayı etkisi, Endüktans verimi, Güç elektroniği çeviricileri

\begin{abstract}
Özet: Güç elektroniği devreleri günümüzde yenilenebilir enerji uygulamaları ve enerji depolamak için kaçınılmaz aygıtlardır. Bu güç elektroniği devrelerinin ana elemanlarından biride endüktanstır. Endüktans bir canlının kalbi gibi çalışır, enerjiyi depolar ve çeviriciler de enerjiyi kaynaktan yüke doğru pompalar ve bu sayede yük devresine sürekli akım akışını sağlar. Bu yüzden iyi tasarlanmış bir endüktans çeviriciyi sürekli modda çalıştırmak için oldukça önemlidir ve böylece akım akışı kesintisiz olur. Bu çalış̧mada çeviriciyi sürekli modda çalıştırmak için gerekli bobin seçim kriteri literatürde incelenmiş ve sınır değer koşulu için kullanılan denklemler yardımıyla bulunmuştur. Yine gerekli denklemleri içeren tasarım aşamaları bir örnek uygulama ile gösterilmiştir. Çekirdek ve kabloların endüktans verimi üzerindeki etkisi de bu çalışmada incelenmiştir. Ferit çekirdek ve Litz teli kullanılan bir endüktans önerilmiş ve bir çevirici devresi için deneysel olarak tasarlanmıştır. Endüktans değerinin belirlenmesi için ölçümler gösterilmiştir. Ayrıca endüktans akım değişimleri yüksek frekanslar için araştırılmış, çeviricide kullanımı gösterilmiştir.
\end{abstract}

\section{Introduction}

The energy harvesting from renewables, and also using it more efficient is an important topic for the scientific researchers today. The power electronics circuits and devices are the main parts for renewable energy applications and also to be storable the energy efficiently. The scientific researchers are focused on design and control of the converters, and also increases the efficiency of the power electronic circuit's components.

One of the main components of the power electronics circuits is inductances. The electrical energy is stored in the inductance temporarily in switch mode power converters. The inductance; which is like the heart in a human which storage and pump the blood, the storage the energy temporarily and pumps the energy from the source to load in switch mode converters, and supply continuously and the circuit current on the load [1, 2].

The energy efficiency of converters depends of course on the inductance efficiency. So a well-designed inductance is very important for the converter in continuous mode operation and continues the current to flow uninterrupted. The inductance value determines how to operate the converter under load 
condition. There is a limit value for the converter to work in continuous and non-continuous mode. The inductance limit value is calculated for this criterion [3-5].

On the other hand, the switching frequency of the converter is related directly to the inductance size. To reduce the inductance size, the switching frequency can be selected to be more than $1 \mathrm{MHz}$ in some applications.

Inductance design is an important research matter. It is possible to find more documents and papers about the calculation process and most of them are belong MAGNETICS Trade Company and the other corporations [6-9]. Also, it is possible to find software tools to calculate and give inductance values [10]. These studies are trying to generalize the method in a simple way. The first step in the design is to select a core for a suitable geometry and also materials [11]. An inductance with powder, sheet and ferrite cores made from different materials and Litz wire for winding are proposed and designed experimentally for a converter circuit $[12,13]$. These special designs aim to reduce all the losses in the inductance [4]. The hysteresis curves of this inductance define the energy density, volume and wire turn [14]. Some differently designed inductances are found in literature such as a printed circuit board (PCB) design. This inductance design is aiming towards a compact and small system and also to solve the mutual inductance problem [1518].

The winding area, winding resistance, and air gap length are the other main topics for inductance design. The calculation and details of these matters are important for the design of the inductance. The correct winding area calculation reduces the winding resistance, and air gap length which affects the inductance design. [12, 13, 20].

In this paper, suitable inductance selection criteria for power converters are investigated in detail and solved by using electromagnetics equations. Also, the design steps of inductance, necessary calculations, and information are shown with an example application. The cores and wires effect on the inductance efficiency are also investigated. An inductance with a Ferrite core and a special manufactured Litz wire is proposed, and designed experimentally for a converter circuit. Measurement for determination of an inductance value is shown. Also, the inductance current variations for different frequencies are studied and to be used in the converter safely.

\section{Inductance Effect and Selection Criteria for Power Converters}

The energy efficiency of converters depends a lot on the inductance efficiency and a well-designed inductance is very important for the converter in continuous conduction mode. The inductance value is determining how to work the converter under different load conditions. The converters inductance voltage and currents are changes with switching signal as shown in Figure 1(a) The converter inductance current and voltages variations with PWM signal for continuous conduction mode is shown in Figure 1(b). The converter inductance current and voltages variations for discontinuous conduction mode are shown in Figure 1(c). In the turn off interval of the switching signal, the inductance current goes to zero with time in this mode. There is a limit value for the converter where it works in continuous and discontinuous mode. The inductance limit value is typically calculated for this criterion. Inductance current and voltage variation for the limit of continuous and discontinuous conduction mode is given in Figure 1(d) for a buck-boost converter circuit. The critical inductance value is calculated using this figure geometry. If the inductance current is above zero all in time the converter works in continuous conduction mode, else the converter works in discontinuous conduction mode. In this mode, the inductance voltage is going to zero and does not supply the load in a short time and the capacitor could also supply the load.

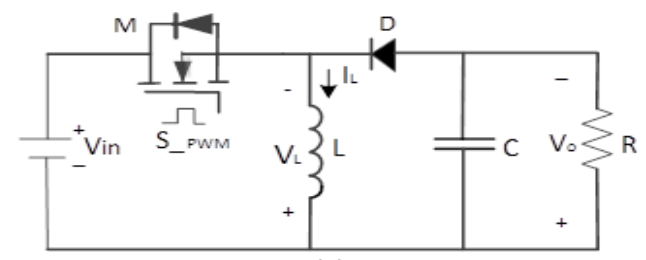

(a)

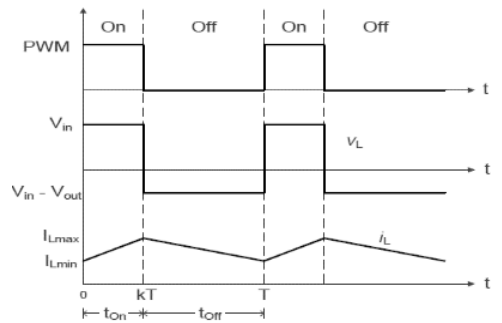

(b)

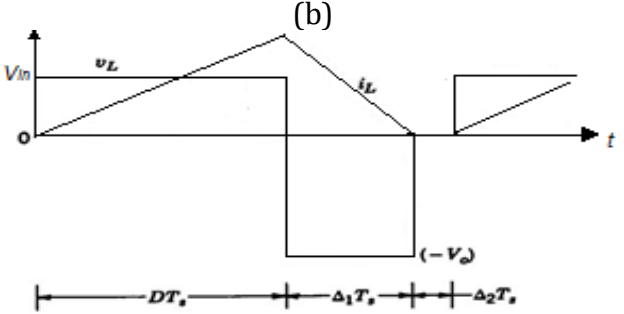

(c)

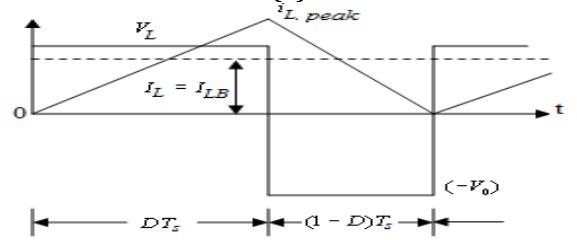

(d)

Figure 1. Buck-boost converter circuit (a), Inductance current and voltage variation; with PWM signal at the continuous mode (b), at the discontinuous mode (c) limit value between continuous and discontinuous mode (d) 
Equation 1 can be written from Figure 1 (b).

$$
I_{L B}=\frac{1}{2} i_{L_{-} p e a k}=\frac{T_{S} V_{\text {in }}}{2 L} D
$$

If the capacitor current in Figure 1(a) is accepted zero, the inductance current is equal to input and output current sum for the converter. Using these equations, the inductance current average value $\left(I_{L B}\right)$ and the output current depends on the output voltage for the limit values $\left(I_{O B}\right)$ given in Equation 2 and 3 respectively. Equation 2 derived from Equation 1 using the relation between input and output voltage of the converter.

$$
\begin{gathered}
I_{L B}=\frac{T_{S} V_{O}}{2 L}(1-D) \\
I_{O B}=\frac{T_{S} V_{O}}{2 L}(1-D)^{2}
\end{gathered}
$$

The maximum values of $I_{L B}$ and $I_{O B}$ for the buck-boost converter have reached this value when the duty ratio is zero and this is given in Equation 4. This equation gives the minimum inductance value for the limit of continuous mode operation.

$$
I_{L B_{-} \max }=I_{O B_{\_} \max }=\frac{T_{S} V_{O}}{2 L}
$$

\section{Design Steps of Inductance}

The necessary calculations for inductance design will be given more detailed in this section with an example using the related documents and studies [6$9,13,14,17]$. The electromagnetic equations of inductance, core structures, and necessary calculations for wire effect and structures as well as power loses relation are also investigated.

The main component in inductance design is the core structure where to be used for magnetic flux flow is provided. Air cores, iron cores, ferrite and powder cores are known inductance cores. Ferrite and powder cores are preferred for high switching frequency power converters having less loses and saturation. Ferrite cores are cheaper and have low power losses at higher switching frequencies but the flux level is lower. These cores are obtained from Mn$\mathrm{Zn}$ and Ni-Zn alloys and have F, P, R, K types depending on the alloy's ratios [8]. Also, the air gap in cores makes it preferable against the saturation. Powder cores have an air gap dispersed in the material due to the nature of the material from which they are produced, and this feature is ideal for switching rectifiers. In addition to a soft saturation characteristic, this feature provides a lot of design convenience, such as small core volume, overcurrent protection, low heat, and powder cores provide high levels of DA magnetic force characteristics without saturation $[4,8]$.
The other matter for core selection is core geometry and it is possible to find pot, E shape, toroid cores and the others in manufacturer catalogues depending on their applications. Pot cores, when assembled are nearly surrounded the wound bobbin and this aids in shielding the coil from picking up EMI from outside sources. Double slab and RM cores are also similar to pot cores but are designed to minimize board space, providing at least a $40 \%$ savings in the mounting area. EP Cores are round centre-post cubical shapes which enclose the coil completely except for the printed circuit board terminals. PQ cores are designed especially for switched mode power supplies. The design provides an optimized ratio of volume to the winding area and surface area. E cores are less expensive than pot cores and have the advantages of simple bobbin winding plus easy to assemble. Also, E cores can be mounted in different directions, and if desired, they provide a low profile. EC, ETD, EER and ER shapes are a cross between E cores and pot cores. Like E cores, they provide a wide opening on each side. Toroid cores are economical to manufacture; hence, they are the least costly of all comparable core shapes. Since no bobbin is required, accessory and assembly costs are nil, but winding is done on toroidal winding machines. Ferrite geometries offer a wide selection in shapes and sizes. To choose a core for power applications the parameters in Table 1 can be used and evaluated [7, $9,17,19]$. Different shapes of Ferrite core types are shown in Figure 2 [22].

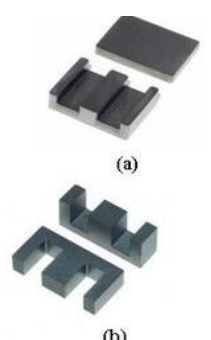

(b)
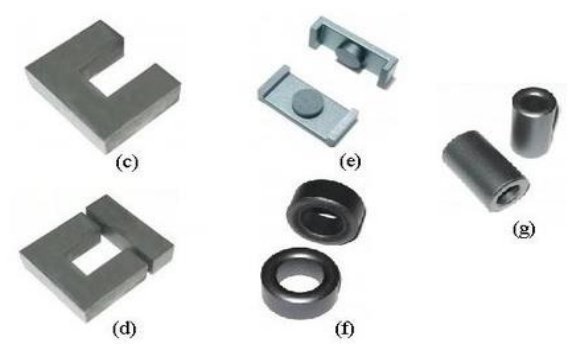

Figure 2. Different shapes of Ferrite cores; (a) E-I core, (b) E-E core, (c) U core, (d) U-I core, (e)EER core, (f) Toroid core, (g) Tube core [22]

E cores are more advantageous in terms of core, coil and winding prices and easy to use, also with cross-sectional area and window spacing of different sizes. E cores have a double flux path which reduces their dimensions and this allows for small footprint and easy installation on printed circuits. E cores air gap can be adjusted, but the fringe fluxes formed in cores with air gap lead to flow losses and eddy current (Eddy) losses on winding wires as shown in Figure 3 (a). Therefore, Kool M $\mathrm{E}$ E powder cores with an equal air gap as shown in Figure 3 (b) are more preferred. The 10.500 gauss saturation level of the Kool $\mathrm{M} \mu \mathrm{E}$ powder cores provides higher energy storage capability that they can be achieved with the air gap ferrite E-cores, which means a smaller core size $[19,20]$. 
Table 1. Comparison of ferrite core geometry types [7]

\begin{tabular}{llllllll}
\hline Core Type & $\begin{array}{l}\text { POT } \\
\text { CORES }\end{array}$ & $\begin{array}{l}\text { DOUBLE } \\
\text { SLAB, RM } \\
\text { CORES }\end{array}$ & $\begin{array}{l}\text { EP } \\
\text { CORES }\end{array}$ & $\begin{array}{l}\text { PQ } \\
\text { CORES }\end{array}$ & $\begin{array}{l}\text { E } \\
\text { CORES }\end{array}$ & $\begin{array}{l}\text { EC, ETD, EER, } \\
\text { ER CORES }\end{array}$ & TOROIDS \\
\hline Core Cost & High & High & Medium & High & Low & Medium & Very Low \\
\hline Bobbin Cost & Low & Low & High & High & Low & Medium & None \\
\hline Winding Cost & Low & Low & Low & Low & Low & Low & High \\
\hline Winding Flexibility & Good & Good & Good & Good & Excellent & Excellent & Fair \\
\hline Assembly & Simple & Simple & Simple & Simple & Simple & Medium & None \\
\hline Mounting Flexibility & Good & Good & Good & Fair & Good & Fair & Poor \\
\hline Heat Dissipation & Poor & Poor & Poor & Good & Excellent & Good & Good \\
\hline Shielding & Excellent & Good & Excellent & Fair & Poor & Poor & Good \\
\hline
\end{tabular}
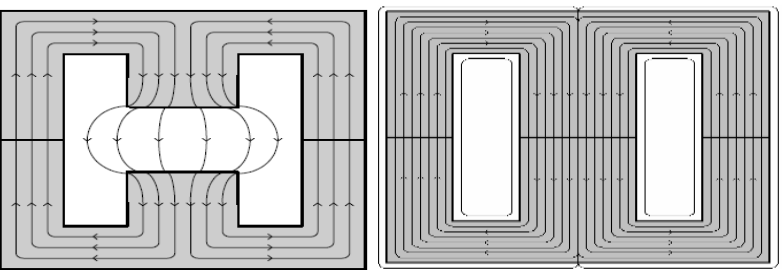

Figure 3. E cores and flux way; gapped Ferrite (a), Kool M $\mu$ (b)

The basic principles of the inductance calculation are based on Faraday's laws. The B-H hysteresis curve between the magnetic flux density (B) and the magnetic field strength $(\mathrm{H})$ for the inductance is given in Figure 4 (a). The relation between $B$ and $H$ are given in Equation 5 according to Figure 4 and magnetic permeability, which is equal to the product of the magnetic permeability of air and core. The magnetic permeability of the air $\mu_{o}=1.26 \times$ $10^{-6} \mathrm{H} / \mathrm{m}$, the magnetic permeability of the material $\mu$ varies between 2000-4000 for Ferrite materials [14]. As the $\mu$ value increases, the B-H curve will reach a linear saturation as shown in Figure 4 (b). Therefore, the magnetic flux density must be selected small.

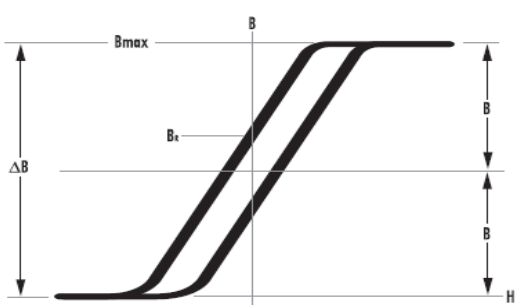

(a)

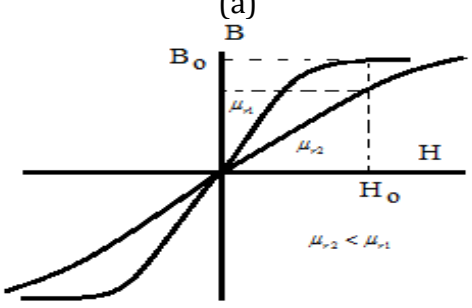

(b)

Figure 4. B - H hysteresis curve (a), the change of the B - H curve with different $\mu$ values (b)

The relationship between the magnetic flux density (B) and the magnetic field strength $(\mathrm{H})$ is given in Equation 5 and gives the permeability of the core.

$\mu=\frac{\Delta B}{\Delta H} \rightarrow B=\mu \times H=\mu \times \mu_{o} \times H$
The inductance value is calculated using Equation 4 and the inductance value is calculated as a $0.72 \mathrm{mH}$ for the maximum power current which is given as an 8.5 A and for the switching frequency. The maximum energy can be stored on the inductance is calculated for this maximum current in Equation 6.

$L I^{2}=\left(0.72 \times 10^{-3}\right) \times(8.5)^{2}=52.02 \times 10^{-3}$ Joule

The Hanna curve obtained from the relation between $\mathrm{B}$ and $\mathrm{H}$ in Equation 6 is given in Figure 4 (a). $V_{e}$ is defined as the volume in this equation.

$$
H=\frac{L I^{2}}{V_{e} B_{\max }}
$$

If the centre of the scale on the Hanna curve is selected as seen in Figure $5(\mathrm{a})$ the volume value $\left(V_{e}\right)$ can be calculated as in Equation 8.

$\frac{L I^{2}}{\text { Volume }}=5.10^{-4} \rightarrow$ Volume $=\frac{52.02 \times 10^{-3}}{5 \times 10^{-4}}=104.04 \mathrm{~cm}^{3}$

The nearest volume value from the E-type core catalogue of the manufacturer is $120 \mathrm{~cm}^{3}$ for the coded DMR40-EE70. The catalogue data for this core is given in Figure 5 (b).

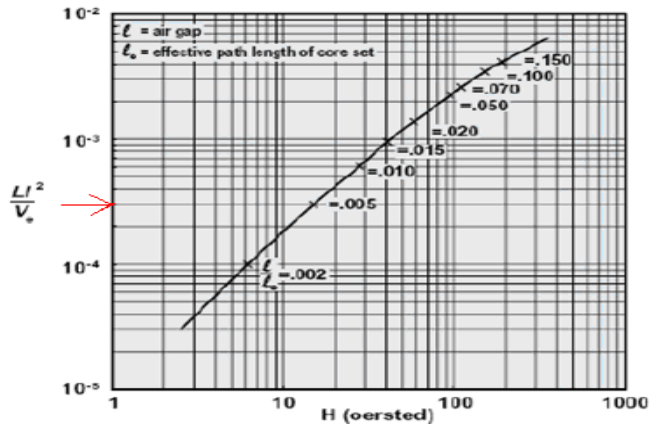

(a)
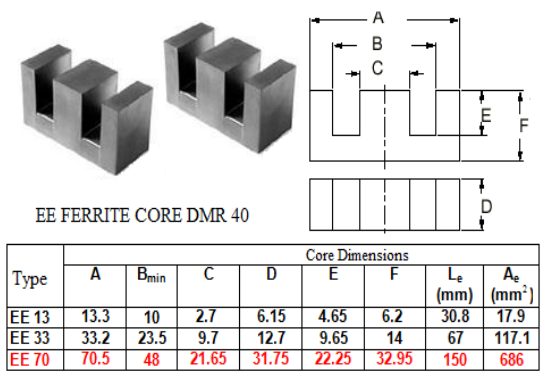

(b)

Figure 5. Hanna curve (a), catalogue data (b) of E-type ferrite core 
For this volume value, the flux path, $\mathrm{Le}=150 \mathrm{~mm}$ and the flux path cross-sectional area is given as $A_{e}=686$ $\mathrm{mm}^{2}$. For new volume value selected is given in Equation 9.

$\frac{L I^{2}}{\text { Volume }}=\frac{52.02 \times 10^{-3}}{102}=0.51 \times 10^{-3} \mathrm{~cm}^{3}$

If we look again at the Hanna curve in Figure 4 (a), it is found for the $\frac{L I^{2}}{\text { Volume }}$ corresponds to value $\frac{l}{l_{e}}=$ 0.005 and $\mathrm{H}=20$. The winding number of the magnetic force from the Oersted expression in Equation 10 is found as:

$H=\frac{0.4 \pi N I}{l_{e}} \rightarrow N=\frac{H l_{e}}{0.4 \pi I}=\frac{20 \times 14.9}{0.4 \times \pi \times 8.5}=27.91 \cong 28$ winding

The cable cross-section to be used for the winding of the current $I_{L B_{\text {max }} \text { ax }}=13.8 \mathrm{~A}$ is selected from the standard table as $1.5 \mathrm{~mm}^{2}$.

The next step is the selection of the type of wire to be used. The effect of the skin phenomenon at high frequencies and the proximity effect of the cables adversely affect the uniform distribution of the current in the conductive wire as seen in Figure 6 (a) and (b) $[12,21]$.

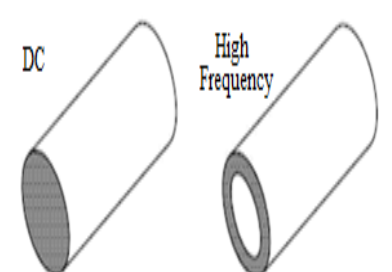

(a)

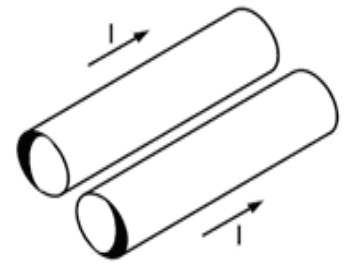

(b)
Figure 6. Skin effect with high frequency (a), and the effect of closure effect of the wire (b)

Various solutions have been proposed to eliminate the effects of skin phenomenon. The major ones are the use of multi-stranded Litz wires, the use of multicore winding cables or the use of ribbon cables [21]. The cross sections of this type of wires are shown in Figure 7.

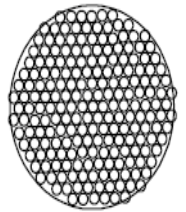

(a)

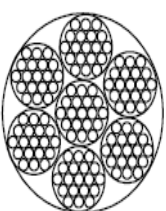

(b)

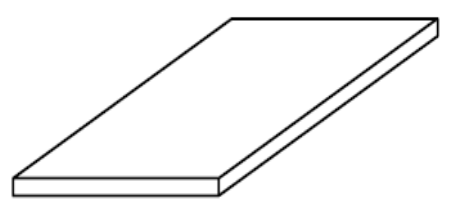

(c)
Figure 7. Various vires cross sections; (a) Litz wire, (b) multi-core wire, (c) strip wire

According to the catalogue data for Litz wire, the cable cross section is taken as two times for the same load flow capacity and the cross-section area for a single wire and required window spacing is calculated as given in Equation 11, 12.

$$
\begin{aligned}
& A_{w}=2 \times 1.5 \times 10^{-2}=3 \times 10^{-2} \mathrm{~cm}^{2} \\
& W_{A}=3 \times 10^{-2}\left(\frac{42}{0.4}\right)=263 \times 10^{-2}=2.63 \mathrm{~cm}^{2}
\end{aligned}
$$

The window spacing for the DMR40-EE70 coded E core can be calculated as in Equation 13 using Figure 5 (b) catalogue data. This value is greater than the calculated value for wire winding and the core window spacing is sufficient.

$$
W_{A}=E(B-C)=5.86 \mathrm{~cm}^{2}
$$

There is no need for an air gap calculation for Kool powder core materials with an equal air gap as mentioned before. Air gap for the Ferrite cores can be calculated as in Equation 14.

$\frac{l}{l_{e}}=0.005 \rightarrow I=14.9 \times 0.005=0.0745 \mathrm{~cm}$

\section{Experimental Design for an Application}

Realization of the inductance experimentally, measurements of inductance value, and study condition under current are given in this section. In accordance with the calculations, the required inductances are designed by using Litz wire, which is specially wrapped with the appropriate coil supplied from the market. The E cores are combined together with a frame where the windings wound are as shown in Figure8 (a). So, the electromagnetic flux will be flow in this core without any leakage. The last appearance of the designed inductance with Litz wire wound and fixed on a frame is shown in Figure 8 (b). Considering the unexpected situations in use, losses and sudden loadings, the winding numbers and therefore the inductance values were selected a little too large.

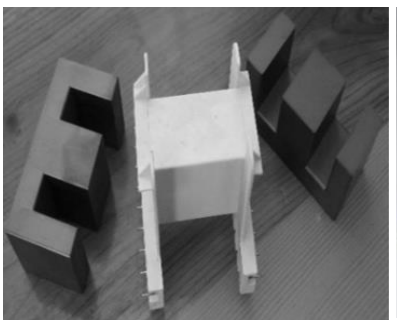

(a)

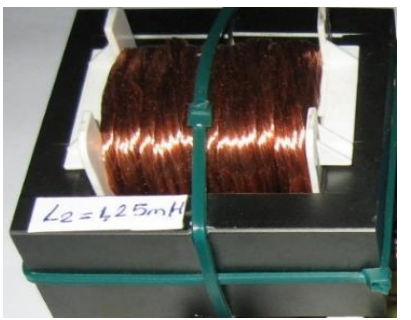

(b)
Figure 8. The used E cores with a frame (a), designed inductance with Litz wire wound and fixed on a frame(b)

The next step is the measurement or to determine the inductance value. Using an LCR meter and measure the inductance value is an easy method. Alternatively, an LC resonance circuit can be used to estimate the inductance value by applying different frequencies. The value of the designed inductance is measured to be $1.2 \mathrm{mH}$ depend on the winding values which are a few spins more. 
The study of the inductance on a switch mode power converter is shown in Figure 8. The inductance current measured with a current probe which is rated $50 \mathrm{mV} / \mathrm{A}$. Also, the inductance current and voltage are shown in Figure 9 for a duty cycle of 0.5 . When the voltage is applied to the inductance the current increases linearly and when the voltage is not applied the current is continuous to flow through the inductance and the inductance behaves as a voltage source. This cycle is called a continuous mode. For the circuit, the switching frequency is $29.2 \mathrm{kHz}$ and inductance maximum current is $5 \mathrm{~A}$ for this application.

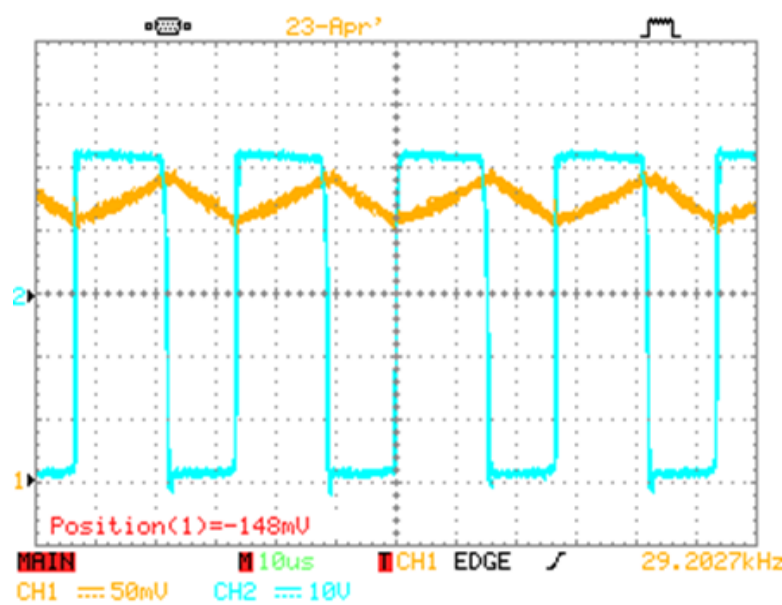

Figure 9. Inductance voltage variation with current for a buck-boost converter circuit. CH1 (Inductance current 50 $\mathrm{mV} / 1 \mathrm{~A}$ ), $\mathrm{CH} 2$ (Inductance voltage)

\section{Conclusion}

The inductance selection criteria and design steps for power electronics applications which are scattered and rarely found in the literature and manufacturer catalogues are investigated in this paper in more detailed. Different studies and applications in literature are used and expanded with an example and application as a fundamental study for researchers who will study on inductance design. Inductance operation and selection criteria for power converters are firstly given in this paper more detailed as a guideline for researchers with a methodology. Inductance effect and selection criteria are investigated for a buck-boost converter design. The calculations and the design steps of inductance related to these criteria are also given more detail. In the experimental and the application part, measurement of the inductance value and behaviour for power converters are given. These results show that the designed inductance supplied the expectation. This study has brought together different studies on this subject and created a fundamental and useful resource for researchers. The losses, efficiency, heat increase of designed inductance and electromagnetic interference for electromagnetic compatibility can be investigated in the future.

\section{Acknowledgment}

This study was supported through The Scientific \& Technological Research Council of Turkey (TUBITAK), project number, 111E292. The authors wish to thank for the support of TUBITAK. Also, the authors wish to thank Prof. Halil İbrahim Okumuş from KTU/Turkey and Prof. Frede Blaabjerg from Aalborg University/Denmark for the contributions.

\section{References}

[1] Mohan, N., Undeland, T. M., Robbins, W. P. 1995. Power Electronics. John Wiley, USA, 832p.

[2] Khalig, A. Nie, Z. Emadi, A. 2009. Integrated Power Electronic Converters and Digital Control. CRC Press, Boca Raton, 350p.

[3] Shaiu, J. K., Cheng, C. J. 2010. Design of a noninverting synchronous buck-boost DC/DC power converter with moderate power level. Robotics, and Computer-Integrated Manufacturing, 26(3), 263-267.

[4] You, B. G., Kim, J. S., Lee, B. K., Choi, G. B., Yoo, D. W. 2011. Optimization of Powder Core Inductors of Buck-Boost Converters for Hybrid Electric Vehicles. Journal of Electrical Engineering \& Technology, 6(4), 527-534.

[5] Rylko, M. S., Lyons, B. J., Hayes, J. G., Egan, M. G. 2011. Revised Magnetics Performance Factors and Experimental Comparison of High-Flux Material for High-Current DC-DC Inductors. IEEE Transactions on Power Electronics, 26(8), 21122126.

[6] Fair-Rite Products Corp. 2005. The Effect of Direct Current on the Inductance of a Ferrite Core, Technical Information, 14th Edition, pp:165-169.

[7] Anonim. 2006, Magnetics Corperation, General Core Selection Data Sheet, Section 4, USA.

[8] Mcylayman, C. W. T. 2016. Transformer and inductor design handbook. CRC Press, California, $667 p$.

[9] Aucejo, B., M., Deü, J., Multon, F. B. 2017. Lossouarn Design of inductors with high inductance values for resonant piezoelectric dampin. Sensors, and Actuators A: Physical, 259, 68-76.

[10] Anonim. 2019, Coilcraft Inc, Power Inductor Finder.https://www.coilcraft.com/apps/powgr_ tools/power/. (Erişim Tarihi: 01.03.2020).

[11] Grandi, G., Kazimierczuk, M. K., Massarini, A., Reggiani, U., Sancineto, G. 2004. Model of laminated iron-core inductors for high frequencies. IEEE Transactions on Magnetics, 40(4), 1839-1845. 
[12] Williams, A., 2011. Fundamentals of Magnetics Design: Inductors and Transformers, Lecturer Notes.

[13] Sahin, M. E. 2014. Design and Control of Parallel Connected Buck-Boost Converter for Hybrid Energy System. Ph.D. Dissertation, Karadeniz Technical University, 202p, Trabzon.

[14] Gary, L. J. 2001. Inductors and Transformers. Solid State Tesla Coil, Chapter 4.

[15] Orenchak, G. 1999. Boost Material Improves Inductor Characteristics under DC Bias Conditions, PCIM Article, 1, 1-3.

[16] Sonntag, C. L. W., Lomonova, E. A., Duarte, J. L. 2008. Implementation of the Neumann formula for calculating the mutual inductance between planar PCB inductors. In Electrical Machines, 18th International Conference on IEEE, 6-9 September, Vilamoura, Portugal, 1-6.

[17] Macrelli, E., Romani, A., Wang, N., Roy, S., Hayes, M., Paganelli, R. P., Tartagni, M. 2014. Modeling, design, and fabrication of high-inductance bond wire micro transformers with a toroidal ferrite core. IEEE Transactions on Power Electronics, 30(10), 5724-5737.

[18] Gala, K., Zolotov, V., Panda, R., Young, B., Wang, J., Blaauw, D., 2000, On-chip inductance modeling and analysis. In Proceedings of the 37th Annual Design Automation Conference, 5-9 June, USA, 63-68.

[19] Anonim. 2005. Magnetics Kool, M $\mu$ E-Cores, Technical Bulletin, Bulletin No: KMC-E1, Magnetics.

[20] Şahin, M. E. Okumus, H. I. 2019. Inductance Selection Criteria and Design Steps for Power Electronics Applications. $16^{\mathrm{TH}}$ International Conference of Young Scientists on Energy Issues (CYSENI), 23-24 May, Kaunas, Lithuania.

[21] Ben-Yaakov, S., 2019, Magnetic design, Switch mode DC-DC converters, Part 3, Lecturer slides, http://www.ee.bgu.ac.il/ dcdc/slides/index.ht ml. (Erişim Tarihi: 01.03.2020).

[22] Saeed, R., 2018, Design and characterisation of a high energy-density inductor. Ph.D. Thesis, University of Nottingham, England. 